\title{
Identifying high-need patients with multimorbidity from their illness perceptions and personal resources to manage their health and care: a longitudinal study
}

\author{
Mieke Rijken ${ }^{1,2^{*}}$ (D), José Maria Valderas ${ }^{3}$, Marianne Heins ${ }^{1}$, Francois Schellevis ${ }^{1,4}$ and Joke Korevaar ${ }^{1}$
}

\begin{abstract}
Background: A proactive person-centred care process is advocated for people with multimorbidity. To that aim, general practitioners may benefit from support in the identification of high-need patients, i.e. patients who are high or suboptimal users of health services and/or have a poor quality of life. To develop such support, we examined whether knowledge about patients' illness perceptions and personal resources to manage their health and care is useful to identify high-need patients among multimorbid general practice populations.

Methods: Survey data, collected in 2016 and 2017, of 601 patients with two or more chronic diseases (e.g. COPD, diabetes, Parkinson's disease) registered with 40 general practices in the Netherlands were analysed by logistic regression analysis to predict frequent contact with the general practice, contact with general practice out-of-office services, unplanned hospitalisations and poor health related quality of life. Patients' illness perceptions and personal resources (education, health literacy, mastery, mental health status, financial resources, social support) were included as predictors.

Results: The four outcomes were only weakly associated among themselves (Phi .07-.19). Patients' illness perceptions and personal resources were of limited value to predict potentially suboptimal health service use, but they were important predictors of health related quality of life. Patients with a poor health related quality of life could be identified by their previously reported illness perceptions (attributing many symptoms to their chronic conditions ( $B=1.479, P<.001)$, a high level of concern $(B=0.844, P=.002)$ and little perceived control over their illness $(B=-0.728, P=.006))$ combined with an experienced lack of social support $(B=-0.527, P=.042)$ and a poor mental health status $(B=-0.966, P=.001$ ) (sensitivity $80.7 \%$; specificity $68.1 \%)$.

(Continued on next page)
\end{abstract}

\footnotetext{
* Correspondence: m.rijken@nivel.nl

'Nivel (Netherlands Institute for Health Services Research), PO Box 1568, 3500, BN, Utrecht, The Netherlands

${ }^{2}$ Department of Health and Social Management, University of Eastern Finland, Kuopio, Finland

Full list of author information is available at the end of the article
}

(c) The Author(s). 2020 Open Access This article is licensed under a Creative Commons Attribution 4.0 International License, which permits use, sharing, adaptation, distribution and reproduction in any medium or format, as long as you give appropriate credit to the original author(s) and the source, provide a link to the Creative Commons licence, and indicate if changes were made. The images or other third party material in this article are included in the article's Creative Commons licence, unless indicated otherwise in a credit line to the material. If material is not included in the article's Creative Commons licence and your intended use is not permitted by statutory regulation or exceeds the permitted use, you will need to obtain permission directly from the copyright holder. To view a copy of this licence, visit http://creativecommons.org/licenses/by/4.0/ The Creative Commons Public Domain Dedication waiver (http://creativecommons.org/publicdomain/zero/1.0/) applies to the data made available in this article, unless otherwise stated in a credit line to the data. 
(Continued from previous page)

Conclusions: Multimorbid patients who frequently contact the general practice, use general practice out-of-office services, have unplanned hospitalisations or a poor health related quality of life are largely distinct high-need subgroups. Multimorbid patients at risk of developing a poor quality of life can be identified from specific illness beliefs, a poor mental health status and unmet social needs.

Keywords: Multimorbidity, Person-centred care, Needs, Health service utilisation, Quality of life

\section{Background}

Multimorbidity, defined as the co-existence of two or more chronic conditions in a person [1], has climbed high on the health policy agenda in many countries, as there is increasing awareness of the magnitude it has on individuals and society [2]. Multimorbidity puts a high burden on the life of patients and their families and impacts their functioning, mental health, social relationships, labour participation and financial situation [3-6]. Together with the rapid increase of the multimorbid population [7, 8], this also affects countries' workforce and welfare [9]. In addition, healthcare expenditures related to multimorbidity are high. A recent study in the United Kingdom found multimorbid general practice patients (27\% of the adult general practice population) to account for $53 \%$ of all consultations with general practitioners (GPs), 56\% of the hospital admissions and $79 \%$ of all prescribed medicines [10]. Other studies show similar findings (e.g., [11-13]).

Over the last decade the quality of care for multimorbid patients has become a major concern, as care delivery is often fragmented and uncoordinated, resulting in duplication, inefficiency and suboptimal outcomes [14, 15]. Awareness has raised that managing multimorbidity asks for a person-centred approach $[15,16]$, as the outcomes to strive for are not straightforward and priorities should be set together with the patient based on his/her personal values and circumstances. This requires care professionals to tailor their care to individual needs [17]. In countries where patients are registered with a GP, it is in particular the GP who could play a key role in providing personcentred care. For instance, by developing an individual care plan with the patient, coordinating care or helping the patient to connect with social care and community services. To initiate a person-centred care process proactively, GPs might benefit from support to identify highneed patients among their multimorbid patient population, because of their risk of adverse outcomes such as uncontrolled health problems resulting in a high or suboptimal use of health services (e.g., frequent visits to the general practice, use of general practice out-of-office services, emergency department visits, unplanned hospitalisations) or a poor quality of life.

Inspired by a study in which older patients at risk of developing a frail health status were identified in Dutch general practice [18], we developed an algorithm to search general practice electronic health records (EHRs) to identify multimorbid patients with a high risk of potentially suboptimal use of health services [19]. As information registered in patients' EHRs could not predict future unplanned hospitalisation and we also wanted to identify patients with a high risk of developing a poor quality of life, we conducted a second study to find patient reported predictors of high needs among multimorbid patients, for the purpose of developing a short screening questionnaire that could (additionally) be used in daily general practice. Potential (patient reported) indicators we studied were patients' illness perceptions and personal resources to manage their health and care.

Illness perceptions are patients' personal beliefs about the cause(s) of their illness, the identity of their condition(s) and symptoms attributed, the impact of their illness on their life, whether and how the course of illness could be influenced by medical treatment or their own behaviour, emotional representations and concern [20]. Illness perceptions have proven to be associated with patients' health behaviours [21-23], although the prospective value of single illness perception dimensions for patients' self-management has not been demonstrated [24]. A recent study showed an external local of control, i.e. a belief that life events are outside one's control, to be an important predictor of developing multimorbidity over 10 years [25]. Illness perceptions of chronic patients have also been found to relate to patients' quality of life (e.g. [26, 27]), clinical outcomes (e.g. [28]) and use of health services (e.g. $[29,30])$. Among people with multimorbidity interacting control beliefs and perceived consequences appeared to predict their physical functioning over 6 months [31].

Patients' ability to manage their health and care may depend on the resources they have at their disposal, such as education, income, social support and health literacy. Previous studies among populations with chronic conditions have demonstrated that a low education level and low income relate to worse clinical outcomes and a poor quality of life [32-34]. Specifically among multimorbid populations it was found that people who live alone and/ or have a low level of health literacy are more likely to experience a poor quality of life [35]. .This study had a cross-sectional design, which did not allow to establish 
the predictive value of persons' resources. Moreover, it did not study relations between personal resources and use of health services.

\section{Research questions}

1. To what extent are specific illness perceptions and personal resources of multimorbid patients independent predictors of potentially suboptimal use of health services and/or a poor health related quality of life?

2. Which combinations of illness perceptions and personal resources best predict these outcomes among multimorbid general practice patients, in addition to their demographic and medical characteristics?

\section{Methods}

\section{Study design and sample}

We conducted a longitudinal study, analysing survey data from multimorbid patients who participated in a nationwide panel-study in the Netherlands [5, 36]. Patients with chronic disease(s) are recruited each year from general practices throughout the Netherlands to participate in the panel-study, based on the following criteria: diagnosis of somatic chronic disease(s), aged 15 years or older, not institutionalised, life expectancy longer than 6 months according to the GP, mentally able to participate and adequate command of the Dutch language. Participants complete questionnaires every 6 months for a maximum of 4 years. GPs provide data about the chronic disease(s) registered as ICPC-1 codes [37] with permission of the participants. The panelstudy is registered with the Dutch Data Protection Authority (registration no. 1283171); all data are collected and handled in accordance with the privacy protection guidelines of the Authority.

In this study we included participants who responded to three successive surveys (April and October 2016, April 2017), of which the most recent one included the outcome measures of health service utilisation and health related quality of life, and the previous surveys included measures of patients' illness perceptions (April 2016) and resources (April 2016, except of available social support and health literacy, of which measures were included in the survey of October 2016). Furthermore, participants had to be diagnosed with at least two chronic diseases according to the list developed by $\mathrm{O}$ 'Halloran and colleagues [38]. As the panel-study does not require GPs to provide data about participants' mental health problems (P-chapter of the ICPC), chronic psychiatric or mental health disorders were not taken into account.

\section{Data collection}

\section{Outcome measures}

Potentially suboptimal use of health services: In April 2017 participants were asked to report: 1 . their number of contacts with the GP or the practice nurse in 2016 (including home visits and consultations by telephone; excluding calls for repeat prescriptions), 2. whether they had contact with general practice out-of-office services by telephone or face-to-face in 2016, 3. whether they had one or more unplanned hospitalisations in 2016. For general practice consultations, we chose the cut-off point of $\geq$ nine contacts with the GP or practice nurse based on the distribution in the sample, as we could not rely on (inter-)national consensus or other studies to designate a certain number of contacts as potentially suboptimal. Frequent contact with the general practice may point to unmet needs, perhaps also in the psychological or social domain, whereas acute care use may be preventable to some extent by early detection of health risks and adequate follow-up care. However, we wish to emphasise that frequent contact with the general practice, using general practice out-of-office services and unplanned hospitalisations may be suboptimal from the perspective of proactive care, but do not automatically point to inappropriate use of services, as this will depend on the necessity and urgency to receive medical care in a specific situation. Therefore we use the term 'potentially suboptimal' in this article.

Poor health related quality of life was assessed by the EQ-5D-5L [39], which consists of five items assessing mobility, self-care, performance of usual activities, pain/ discomfort, and anxiety/depression, each with five response options. Based on the preferences of a representative Dutch general population sample, index values were assigned to each of the $3125\left(5^{5}\right)$ possible health states, ranging from -0.446 to 1 [40]. As a formal cutoff point does not exist, we operationalised a poor health related quality of life as a score lower than .67 (boundary of percentile-20 in our study), which is one standard deviation below the reference value of the Dutch general population aged 50 and older [40].

\section{Predictors}

Patients' illness perceptions were assessed by the Brief Illness Perception Questionnaire (BIPQ) [41]. This questionnaire consists of eight items, each referring to another dimension of a person's illness representation, based on the Common Sense Model of self-regulation [20]: personal beliefs about the consequences of one's illness, about the duration, the perceived ability to control the illness by one's own behaviour, beliefs about the extent to which medical treatment helps to control the illness, symptoms experienced and attributed to the disease (identity), concerns, perceived understanding of 
one's illness, and one's emotional response to the illness. In the survey, multimorbid patients were asked to respond to the questions keeping in mind the condition they were suffering from most.

Personal resources were assessed by a set of survey questions measuring various resources:

- Social resources: Participants reported whether they lived together with a spouse or partner. In addition, we included one item of the Loneliness scale [42]: "There are plenty of people I can lean on when I have problems", with three response options (yes, more or less, no).

- Education: Level of education was based on the highest level of completed education. We distinguished three categories: low (primary school or low/preparatory vocational training), medium (intermediate or advanced general education or intermediate vocational training), and high (high vocational education or university).

- Financial resources: We included one item about one's financial situation: "How would you describe your current financial situation?" (answering options: 1: I have to make debts, 2: I need to use my savings, 3: I get by, 4: I save some money, and 5: I save a lot of money) [43].

- Health literacy: Health literacy has been described by the WHO as "the cognitive and social skills which determine the motivation and ability of individuals to gain access to, understand and use information in ways which promote and maintain good health" [44]. We included the Health Literacy Questionnaire (HLQ) [45], which consists of 44 items belonging to nine scales, based on a comprehensive model of health literacy (see Table 2). Five scales have a four-response format (strongly disagree, disagree, agree, strongly agree) and four a five-response format (cannot do, very difficult, quite difficult, quite easy, very easy). Scale scores could range between 1 and 4 for the scales with four response options, and between 1 and 5 for those with five response options. Higher scale scores refer to higher levels of health literacy. Cronbach's alpha coefficients of the nine scales in our study ranged from .71 to .90 , indicating good internal consistency.

- Mastery: Mastery is a psychological resource and has been defined as "the extent to which one regards one's life-chances as being under one's own control in contrast to being fatalistically ruled" [46]. We included a Dutch version [47] of the Pearlin Mastery Scale [46], which consists of five negatively worded and two positively worded items. Unlike the original scale, the Dutch items are scored on a five-response format, from 1 (strongly disagree) to 5 (strongly agree). Scale scores could range between 7 and 35, with higher scores indicating higher levels of mastery. Cronbach's alpha in our study was .81 .

- Mental health: To assess mental health, we included the Depression scale of the Hospital Anxiety and Depression Scale (HADS) [48]. This scale consists of seven items with four answering options, ranging from 0 to 3. Scale scores could range from 0 to 21; a scale score of 8 or higher is considered an indication of a mild or more severe depression [49].

Cronbach's alpha of the scale in our study was .83 .

\section{Statistical analyses}

We conducted univariate analyses to describe the demographic and medical characteristics of the participants as well as their use of health services and health related quality of life. Subsequently, we determined cut-off scores on the measures of patients' illness perceptions and personal resources (see Supplementary file 1). Next, we assessed the associations (Phi coefficients) between the four outcome variables. As these associations appeared to be weak (Phi ranging from .07 to .19), we analysed each outcome variable separately.

To answer our first question, we conducted logistic regression analysis for each outcome variable as the dependent variable and each illness perception dimension or resource separately included as predictor. To answer our second question, we first checked for collinearity (see Supplementary file 1). Next, we conducted two preparatory multivariate logistic regression analyses (see Supplementary file 1) to limit the number of predictors compared to the number of cases in the final multivariate model. In the final multivariate logistic regression model we conducted for each outcome variable we included the patient's age, sex, number of chronic diseases and those illness perception dimensions and resources that had proven to be significant predictors in the bivariate or preparatory multivariate analyses. ROC curves were constructed to assess the specificity and sensitivity of the final prediction models and the area under the ROC curve (AUC). In case of AUC greater than .70 , we determined the most appropriate cut-off value based on the coordinates of the curve, considering that we aimed to predict at least $80 \%$ of the true positives, while also maximizing the proportion of true negatives.

\section{Results}

Participants and drop-out

Of the 1299 panel members with two or more chronic diseases, 747 participated in all three surveys (response rates: April 2016 75\%, October 2016 96\%, April 2017 91\%) (see Fig. 1). Apart from once-only non-response, 


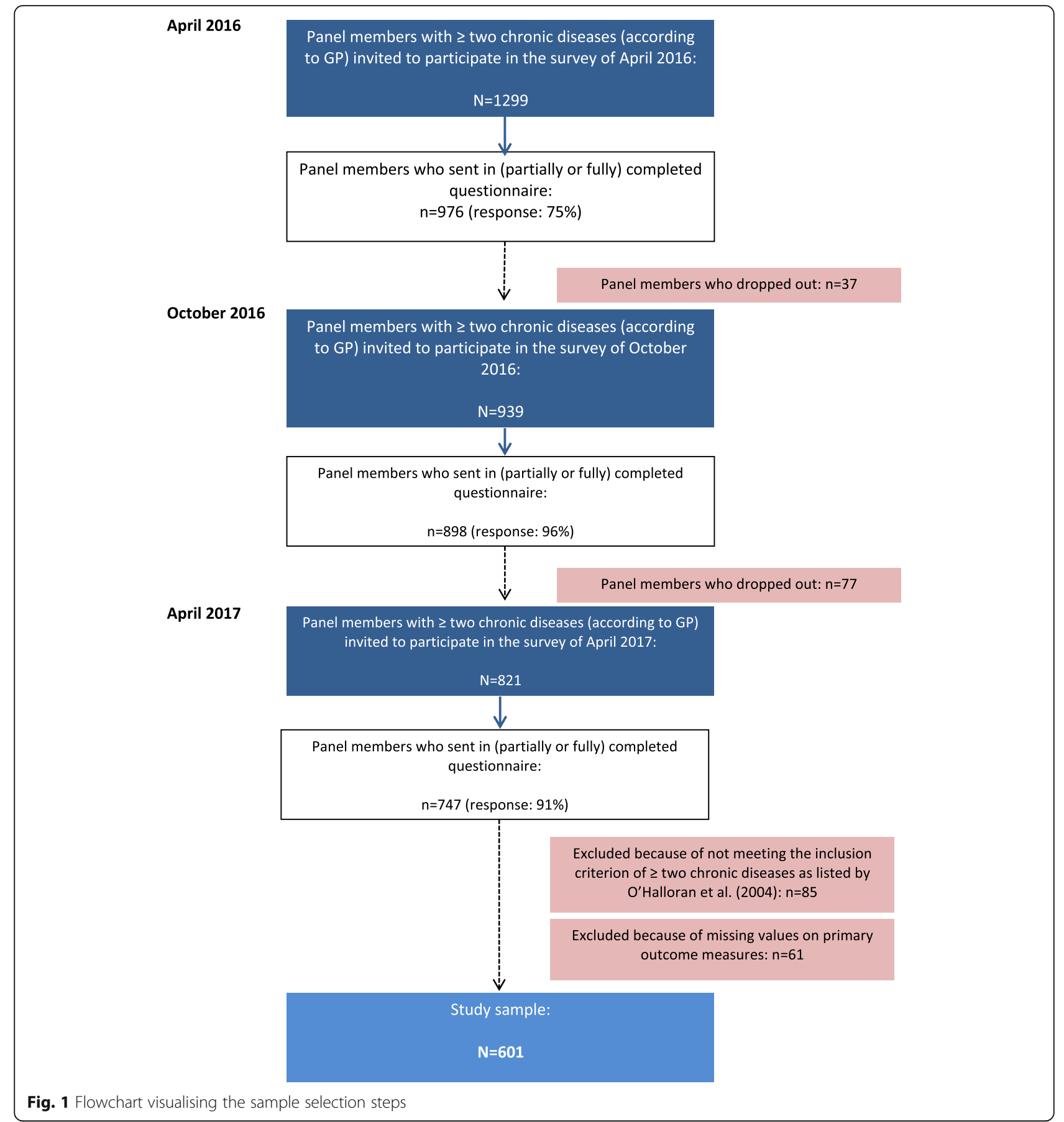

114 persons (9\%) dropped out the panel-study inbetween because of various reasons: they felt the questions did not apply to them $(n=25)$, were too difficult $(n=18)$ or too intimate $(n=6)$, they felt too ill $(n=$ $15)$, they had reached the participation term of 4 years $(n=11)$, because of death $(n=4)$, not interested anymore $(n=6)$, personal reasons $(n=4)$ or unknown $(\mathrm{n}=25)$. In the latter case it concerned persons who did not respond to two successive surveys. Of the 747 responders to all three surveys, we excluded 85 persons because they did not have at least two chronic diseases of the list developed by O'Halloran and colleagues, and 61 because of missing values on the outcome measures. This resulted in a final sample of 601 persons, from 40 general practices throughout the Netherlands. 
Sample characteristics, use of health services and health related quality of life

Gender distribution was 52\% women and $48 \%$ men. The mean age was 69.2 years (SD 9.9 years). Half of the sample $(51 \%)$ had been diagnosed with two chronic diseases, $30 \%$ with three, and $19 \%$ with four or more chronic diseases. Hypertension (34\%), diabetes (29\%) and ischemic heart disease (21\%) had been diagnosed most frequently, followed by osteoarthritis (14\%), asthma (14\%), atrial fibrillation (12\%), COPD (11\%) and hypothyroidism (11\%).

The average number of contacts with the general practice in 2016 was $6.6 ; 23 \%$ reported nine or more contacts (Table 1). 21\% reported to have had contact with the general practice out-of-office service; $9 \%$ reported an unplanned hospital admission in 2016. The mean EQ-5D$5 \mathrm{~L}$ score was 0.77 , with $20 \%$ of the sample scoring below 0.67 ('poor health related quality of life'). $60 \%$ of the sample did not have an indication of potentially suboptimal use of health services or a poor health related quality of life (Fig. 2). Of the remaining 40\%, half had one or more indications of potentially suboptimal use of health services but not a poor health related quality of life.

\section{Illness perceptions and resources}

Participants' illness perception scores showed high levels of understanding of their main condition and relatively low levels of concern and emotional response. Personal control beliefs were rather low (Table 2), indicating that most participants did not believe to have much influence on the course of their illness(es). Regarding their personal resources, about three quarters lived together with a partner. Most participants reported sufficient financial means, but $15 \%$ made debts or had to use savings to make ends meet. With regard to health literacy, most difficulties related to finding good health information, critically appraising the information and resources, and finding out about available services and support ('navigating the healthcare system'). Almost one fifth had an indication of a depression.

\section{Results of bivariate analyses}

None of the illness perception dimensions was a significant predictor of more than one indicator of potentially suboptimal use of health services (Table 3), except participants' emotional response to their illness, which increased both the likelihood of frequent contact with the general practice and of contact with general practice out-of-office services. Control beliefs were the only significant predictor of unplanned hospitalisations: people who perceived high control over their illness, were less likely to report an unplanned hospitalisation. In contrast, all illness perception dimensions, except perceptions regarding the timeline, were significant predictors of a

Table 1 Use of health services and health related quality of life of participating multim006Frbid patients

\begin{tabular}{|c|c|c|c|c|}
\hline & N & Mean (SD) & $\mathrm{n}$ & $\%$ \\
\hline \multicolumn{5}{|l|}{ Use of services in previous year (self-reported; April 2017) } \\
\hline Number of consultations general practice (GP and practice nurse): & 593 & $6.56(6.45)$ & & \\
\hline 0 & & & 25 & 4.2 \\
\hline 1 to 4 & & & 220 & 37.1 \\
\hline 5 to 8 & & & 213 & 35.9 \\
\hline 9 to 12 & & & 84 & 14.2 \\
\hline More than 12 & & & 51 & 8.6 \\
\hline Contact with general practice out-of-office service: (ref. no contact) & 601 & & 124 & 20.6 \\
\hline only by telephone & & & 35 & 5.8 \\
\hline (also) consultation(s)/visit(s) & & & 89 & 14.8 \\
\hline Hospital admission(s): (ref. no) & 597 & & & \\
\hline Yes & & & 104 & 17.4 \\
\hline Unplanned hospitalisation(s): (ref. no) & 596 & & & \\
\hline Yes & & & 54 & 9.1 \\
\hline Total number of nights in hospital & 588 & & & \\
\hline 0 & & & 493 & 83.8 \\
\hline 1 to 4 & & & 60 & 10.2 \\
\hline 5 or more & & & 36 & 6.1 \\
\hline Health related quality of life (EQ-5D index value; April 2017) & 601 & $0.77(0.22)$ & & \\
\hline Poor health related quality of life (index value $<0.67$ ) & 601 & & 118 & 19.6 \\
\hline
\end{tabular}



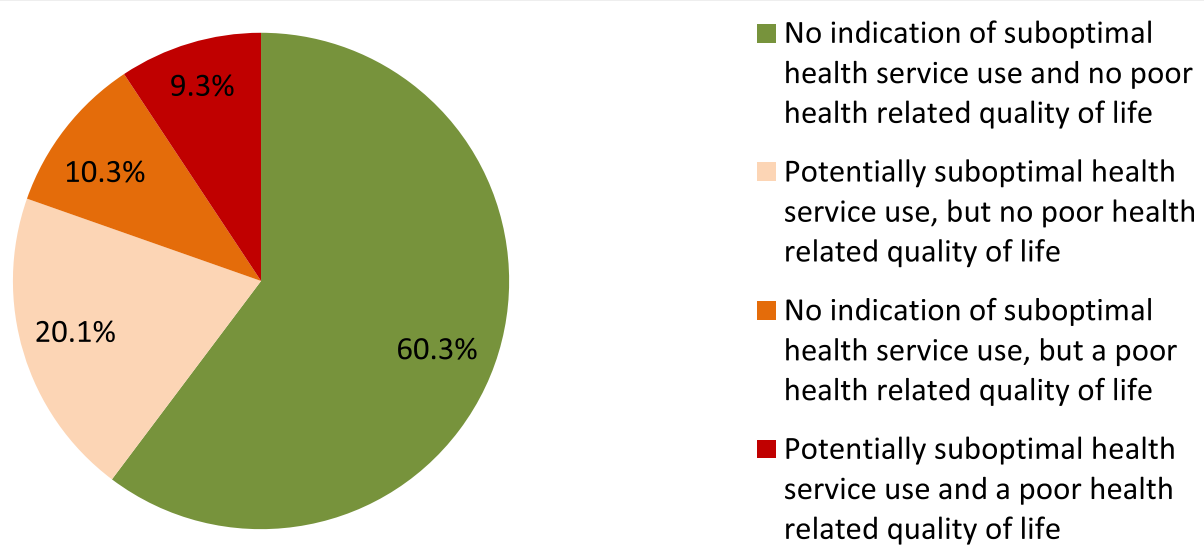

Fig. 2 Distribution of multimorbid patients according to health service use and health related quality of life ( $N=601)$

poor health related quality of life. Similarly, many resource variables were significant predictors of a poor health related quality of life, whereas none of these significantly predicted the use of general practice out-ofoffice services and unplanned hospitalisations. Having limited personal resources appeared to predict frequent contact with the general practice, in particular having a low level of health literacy (experiencing difficulties in navigating the healthcare system and in reading and understanding health information), lacking a sense of mastery and feeling depressed.

\section{Results of multivariate analyses}

Including all significant predictors from the previous analyses in one multivariate model (Table 4) showed that sex (female), a high level of concern and lacking a sense of mastery increased the likelihood of frequent contact with the general practice. The use of general practice out-of-office services was predicted by age $(75+)$ and a strong emotional response to one's condition(s). Perceiving high personal control over one's illness decreased the likelihood of unplanned hospitalisations. Perceiving high control also decreased the chance of a poor health related quality of life, whereas attributing many symptoms to one's condition(s) and a high level of concern increased the likelihood of experiencing a poor health related quality of life 12 months later. A belief that social support was sufficiently available as well as a good mental health status decreased the likelihood of a poor health related quality of life 12 months later.

\section{Classification}

Prediction of frequent contact with the general practice, use of general practice out-of-office services and unplanned hospitalisations was poor $(\mathrm{AUC}<.70)$, whereas prediction of poor health related quality of life by the final model was acceptable (AUC .837) (Table 5). Based on the coordinates of the curve provided by the ROC analysis, we determined a cut-off value of .16 most optimal, considering that we aimed to identify at least four out of five persons with a poor health related quality of life 12 months later, while also classifying correctly as many persons possible who did not experience a poor health related quality of life.

\section{Discussion}

Multimorbid patients' perceptions of their illness and personal resources appear of little value to predict who will frequently contact the general practice, use general practice out-of-office services or have unplanned hospitalisations. Assessing patients' illness perceptions and resources may however be helpful to identify which multimorbid patients have a high risk of developing a poor health related quality of life. This applies in particular to certain illness beliefs (attributing many symptoms to one's chronic condition(s), being very concerned and experiencing little control over one's illness) and resources (a poor mental health status, little social support).

The predictive value of patients' illness perceptions for quality of life is in line with previous cross-sectional and longitudinal studies among chronic patients [26, 27, 50,51]. This also holds for the predictive value of specific illness perception dimensions for health service use [52]. For instance, we found patients' level of concern to be a significant predictor of frequent contact with the general practice, which is in line with a study among survivors of endometrial cancer, which showed survivors with higher levels of concern to be more likely to visit their GP or medical specialist [53]. Considering the role of patients' resources, we found many to be significant predictors of health related quality of life in the bivariate analyses, which is in line with other studies (e.g. [32-35, 54]), but few remained their significance in the multivariate model. Moreover, hardly any resources we included were significant predictors of potentially suboptimal service use. The bivariate models show 
Table 2 IIIness perceptions and personal resources of participating multimorbid patients

Illness perceptions

Consequences (0-10)

584

Mean (SD)

N

$\%$

Consequences dichotomous (score $\geq 7$ )

Timeline (0-10)

Timeline dichotomous (score $\geq 7$ )

\section{2}

Personal control (0-10)

Personal control dichotomous (score $\geq 7$ )

Treatment control ${ }^{\mathrm{a}}(0-10)$

Treatment control dichotomous (score $\geq 7$ )

Identity (0-10)

Identity dichotomous (score $\geq 7$ )

Concern (0-10)

Concern dichotomous (score $\geq 7$ )

Understanding (0-10)

Understanding dichotomous (score $\geq 7$ )

Emotional response (0-10)

Emotional response dichotomous (score $\geq 7$ )

\section{Personal resources}

\section{Social resources}

Lives with partner

There are plenty of people I can lean on when I have troubles

No

More or less

Yes

\section{Education level}

Low (primary school or low/preparatory vocational training)

Medium (intermediate or advanced general education or intermediate vocational training)

High (applied university, university)

\section{Financial resources}

How would you describe your current situation?

I have to make debts

I need to use my/our savings

I get by

I save some money

I save a lot of money

\section{Health literacy}

Healthcare provider support (HPS) (1-4)

HPS dichotomous (score $\geq 3$ )

Having sufficient information (HSI) (1-4)

HSI dichotomous (score $\geq 3$ )

Actively managing health (AMH) (1-4)

$\mathrm{AMH}$ dichotomous (score $\geq 3$ )

Social support (SS) (1-4)

SS dichotomous (score $\geq 3$ )

Critical appraisal (CA) (1-4)
580

570

$9.03(1.85)$

$\begin{array}{ll}205 & 35.1 \\ 246 & 42.1 \\ 133 & 22.8\end{array}$


Table 2 IIIness perceptions and personal resources of participating multimorbid patients (Continued)

\begin{tabular}{|c|c|c|c|c|}
\hline Illness perceptions & $\mathrm{N}$ & Mean (SD) & $\mathrm{N}$ & $\%$ \\
\hline CA dichotomous (score $\geq 3$ ) & & & 182 & 31.9 \\
\hline Active engagement with healthcare providers (AE) (1-5) & 559 & $3.88(0.64)$ & & \\
\hline AE dichotomous (score $\geq 4$ ) & & & 328 & 58.7 \\
\hline Navigating the healthcare system (NHS) (1-5) & 563 & $3.74(0.65)$ & & \\
\hline NHS dichotomous (score $\geq 4$ ) & & & 244 & 43.3 \\
\hline Ability to find good health information (FHI) (1-5) & 557 & $3.72(0.67)$ & & \\
\hline FHI dichotomous (score $\geq 4$ ) & & & 259 & 46.5 \\
\hline Reading and understanding health information $(\mathrm{UHI})(1-5)$ & 560 & $3.83(0.61)$ & & \\
\hline UHI dichotomous (score $\geq 4$ ) & & & 287 & 51.3 \\
\hline Mastery & 581 & & & \\
\hline Mastery scale score (7-35) & & $23.40(5.11)$ & & \\
\hline Mastery scale score $>21$ & & & 379 & 65.2 \\
\hline Mental health & 584 & & & \\
\hline HADS depression scale score (0-21) & & $4.48(3.76)$ & & \\
\hline High-risk major depression (scale score $\geq 8$ ) & & & 112 & 19.2 \\
\hline
\end{tabular}

a only filled in if applicable (perceived by participants as in case of medical treatment); $n=94$ chose the n.a.-option

several aspects of health literacy and mastery to be predictive of (not) frequently contacting the general practice or using out-of-office services, which is in line with other studies $[35,55]$, but only mastery remained its significance in the multivariate model predicting frequent contact with the general practice.

An important finding of our study is that multimorbid patients at risk of a poor health related quality of life are for a large part not the same patients who frequently contact the general practice, visit the general practice out-of-office service or have unplanned hospitalisations, or vice versa. This also explains why hardly any illness perception dimensions or resources were of predictive value for more than one of these outcomes.

The poor prediction of frequent contact with the general practice, contact with general practice out-of-office services and unplanned hospitalisations may be explained by either the choice of predictors or the nature of these outcomes. To start with the first option, frequent contact with the general practice may be better predicted by data registered in patients' general practice EHR, alone or in combination with patient-reported information, as in healthcare systems where GPs play a big role in chronic disease management contact with the general practice will for a large part not be initiated by the patient. As we mentioned in the introduction, we aimed to develop support for GPs to identify multimorbid patients with a high need for proactive personcentred care based on a two-step procedure: first, applying an algorithm that automatically searches patients' EHRs for indicators of potentially suboptimal use of health services; then applying a short screening questionnaire to assess the illness perceptions and personal resources of the patients selected by the first step, to improve identification of high needs, also taking into account patients' quality of life. Our study to develop the algorithm for the first step [19] confirms that data registered in patients' general practice EHRs are good predictors of future frequent contact with the general practice, but not of unplanned hospitalisations. This brings us to the second option, which may apply in particular to the use of general practice out-of-office services and unplanned hospitalisations: the future use of these services by multimorbid patients may be difficult to predict anyway, regardless of which patient data, clinical or self-reported, we use. Due to the complexity of multimorbidity and related medical treatment (e.g. polypharmacy), unexpected health problems may arise, which necessitates acute care.

\section{Strengths and limitations}

Participants were selected from a nationwide panelstudy, which uses a standardised procedure to randomly select general practices throughout the country, and within these practices, patients with chronic diseases [5]. Although we initially selected 1299 panel members with two or more chronic conditions registered by GPs, our final sample was substantially smaller $(\mathrm{N}=601)$, as for this longitudinal study we only included persons who had responded to three successive surveys over a year, with two or more chronic diseases defined as such by O'Halloran and collleagues (2004) and who did not have missing data on any of the four outcome measures. Statistical analyses comparing the background characteristics 
Table 3 IIIness perception dimensions and resources as predictors of potentially suboptimal use of services and/or a poor health related quality of life, results of multinomial logistic regression analyses with one predictor included per analysis

\begin{tabular}{|c|c|c|c|c|c|c|c|c|}
\hline & \multicolumn{2}{|c|}{$\begin{array}{l}\text { Frequent } \\
\text { contact } \\
\text { with GP }\end{array}$} & \multicolumn{2}{|c|}{$\begin{array}{l}\text { Use of general } \\
\text { practice out-of- } \\
\text { office service }\end{array}$} & \multicolumn{2}{|c|}{$\begin{array}{l}\text { Unplanned } \\
\text { hospitalisation }\end{array}$} & \multicolumn{2}{|c|}{$\begin{array}{l}\text { Poor health } \\
\text { related quality } \\
\text { of life }\end{array}$} \\
\hline & $\mathbf{N}$ & OR & $\mathbf{N}$ & OR & $\mathbf{N}$ & OR & $\mathbf{N}$ & OR \\
\hline \multicolumn{9}{|l|}{ Illness perceptions } \\
\hline BIPQ Consequences $\geq 7$ (vs < 7 ) & 576 & 1.21 & 584 & 1.42 & 580 & 1.56 & 584 & $5.68^{* * *}$ \\
\hline BIPQ Timeline $\geq 7$ (vs < 7) & 574 & 1.81 & 582 & 0.87 & 578 & 0.98 & 582 & 2.56 \\
\hline BIPQ Personal control $\geq 7$ (vs $<7$ ) & 576 & 0.90 & 584 & 1.01 & 580 & $0.40^{* *}$ & 584 & $0.37^{* * *}$ \\
\hline BIPQ Treatment control $\geq 7$ (vs $<7$ ) & $455^{\mathrm{a}}$ & 0.66 & $460^{\mathrm{a}}$ & $0.64^{*}$ & $457^{\mathrm{a}}$ & 0.61 & $460^{a}$ & $0.29 * * *$ \\
\hline BIPQ Identity $\geq 7$ (vs < 7) & 577 & $1.73^{* *}$ & 585 & 1.13 & 581 & 1.27 & 585 & $7.10^{* * *}$ \\
\hline BIPQ Concern $\geq 7$ (vs < 7) & 564 & $1.94^{* *}$ & 571 & 1.18 & 566 & 1.46 & 571 & $6.58^{* * *}$ \\
\hline BIPQ Understanding $\geq 7$ (vs < 7) & 568 & 1.16 & 575 & 0.84 & 570 & 0.70 & 575 & 0.85 \\
\hline BIPQ Emotional response $\geq 7$ (vs $<7$ ) & 570 & $2.02^{* *}$ & 577 & $1.70^{*}$ & 572 & 1.72 & 577 & $5.55^{* * *}$ \\
\hline \multicolumn{9}{|l|}{ Personal resources } \\
\hline Education level: medium (vs low) & 576 & 0.91 & 584 & 0.86 & 580 & 0.82 & 584 & 0.79 \\
\hline Education level: high (vs low) & 576 & 0.79 & 584 & 0.95 & 580 & 0.74 & 584 & $0.38^{* *}$ \\
\hline "I get by or I save" (vs "I have to make debts or use my savings") & 562 & 0.66 & 570 & 1.20 & 566 & 1.26 & 570 & $0.42^{* *}$ \\
\hline Lives with partner & 589 & 1.00 & 597 & 1.24 & 592 & 1.25 & 597 & $0.65^{*}$ \\
\hline "Have plenty people": yes (vs more or less / no) & 574 & 0.75 & 580 & 1.09 & 575 & 0.94 & 580 & $0.41^{* * *}$ \\
\hline HLQ Healthcare provider support: score $\geq 3$ (vs <3) & 577 & 1.05 & 583 & $0.62^{*}$ & 579 & 0.80 & 583 & 0.70 \\
\hline HLQ Having sufficient information $\geq 3$ (vs $<3$ ) & 569 & 0.70 & 576 & 0.75 & 571 & 0.81 & 576 & $0.51^{* *}$ \\
\hline HLQ Actively managing health $\geq 3$ (vs $<3$ ) & 563 & 1.16 & 570 & 0.77 & 565 & 1.28 & 570 & 1.17 \\
\hline HLQ Social support $\geq 3$ (vs < 3 ) & 569 & 1.02 & 577 & 1.32 & 572 & 1.02 & 577 & 0.96 \\
\hline HLQ Critical appraisal $\geq 3$ (vs < 3) & 564 & 1.21 & 570 & 0.67 & 566 & 0.87 & 570 & 0.90 \\
\hline HLQ Active engagement with healthcare providers $\geq 4$ (vs $<4$ ) & 553 & 0.87 & 559 & 0.68 & 555 & 1.24 & 559 & $0.43^{* * *}$ \\
\hline HLQ Navigating the healthcare system $\geq 4$ (vs < 4) & 557 & $0.62^{*}$ & 563 & 0.75 & 559 & 0.82 & 563 & $0.48^{* *}$ \\
\hline HLQ Ability to find good health information $\geq 4$ (vs $<4$ ) & 551 & 0.73 & 557 & 0.72 & 553 & 1.07 & 557 & $0.54^{* *}$ \\
\hline HLQ Reading and understanding health information: score $\geq 4$ (vs $<4)$ & 554 & $0.66^{*}$ & 560 & 0.77 & 556 & 0.76 & 560 & $0.58^{*}$ \\
\hline Mastery > 21 (vs $\leq 21)$ & 574 & $0.51^{* *}$ & 581 & 0.77 & 577 & 0.62 & 581 & $20^{* * *}$ \\
\hline HADS-Depression < 8 (vs $\geq 8$ ) & 577 & 0.68 & 584 & 0.77 & 579 & 1.39 & 584 & $.16^{* * *}$ \\
\hline
\end{tabular}

of our final sample with the group of excluded persons demonstrated that the two groups had similar distributions of gender, education level and household composition $(P>.05)$. However, our final sample consisted of more people with three or more chronic diseases $(49 \%$ vs $40 \%)$ and less people with two chronic diseases (51\% vs $60 \%$ ) than the group of persons not included in the final sample. Moreover, our final sample was on average slightly older (69,2 years) than the group op persons not included in the final sample (67,3 years). These differences could be explained by respondents who appeared not to have two or more chronic diseases that were recognised as such by O'Halloran et al. (2004), whom we purposefully excluded from the sample before starting data-analysis. Given that the latter respondents did not belong to the study population we aimed to include, we believe our sample to be a good representation of the population we envisaged for this study.

The comprehensive half-yearly surveys provide rich data about participants' illness perceptions and resources, which is very valuable in combination with registration data of chronic diseases.

As there is no valid questionnaire available in Dutch, we used the BIPQ, which has been designed to assess the patient's perception of a single disease or condition. Our multimorbid participants were asked to complete the BIPQ keeping in mind the condition they were suffering from most. This may have resulted in an 
Table 4 Final prediction models of potentially suboptimal use of health services and a poor health related quality of life, results of multivariate multinomial logistic regression analyses

\begin{tabular}{|c|c|c|c|c|}
\hline & $\begin{array}{l}\text { Frequent contact with the } \\
\text { general practice }\end{array}$ & $\begin{array}{l}\text { Use of general practice out- } \\
\text { of-office service }\end{array}$ & $\begin{array}{l}\text { Unplanned } \\
\text { hospitali-Sation }\end{array}$ & $\begin{array}{l}\text { Poor health related } \\
\text { quality of life }\end{array}$ \\
\hline Final model & $\begin{array}{l}\operatorname{Chi}^{2}(3)=21.512 \\
(P<.001)\end{array}$ & $\begin{array}{l}\mathrm{Chi}^{2}(3)=16.037 \\
(P=.001)\end{array}$ & $\begin{array}{l}\operatorname{Chi}^{2}(1)=9.654 \\
(P=.002)\end{array}$ & $\begin{array}{l}\mathrm{Chi}^{2}(7)=137.288 \\
(P<.001)\end{array}$ \\
\hline \multirow[t]{2}{*}{ N } & 552 & 577 & 580 & 541 \\
\hline & B $(P)$ & B $(P)$ & $\mathrm{B}(P)$ & $\mathrm{B}(P)$ \\
\hline Sex: male (ref: female) & $-0.493(.019)$ & & & \\
\hline \multicolumn{5}{|l|}{ Age (ref: younger than 65 years) } \\
\hline 65 to 74 years & & $0.187(.490)$ & & $-0.477(.131)$ \\
\hline 75 years or older & & $0.775(.003)$ & & $0.458(.135)$ \\
\hline \multicolumn{5}{|l|}{ Number of chronic conditions } \\
\hline BIPQ Personal control $\geq 7$ & & & $-0.926(.003)$ & $-0.728(.006)$ \\
\hline BIPQ Identity $\geq 7$ & & & & $1.479(<.001)$ \\
\hline BIPQ Concern $\geq 7$ & $0.446(.048)$ & & & $0.844(.002)$ \\
\hline BIPQ Emotional response $\geq 7$ & & $0.622(.005)$ & & \\
\hline $\begin{array}{l}\text { "I have plenty people": yes (vs } \\
\text { more or less/no) }\end{array}$ & & & & $-0.527(.042)$ \\
\hline HADS-Depression $<8$ & & & & $-0.966(.001)$ \\
\hline Mastery $>21$ & $-0.533(.017)$ & & & \\
\hline Constant & $-0.828(<.001)$ & $-1.838(<.001)$ & $-1.904(<.001)$ & $-1.279(.002)$ \\
\hline $\begin{array}{l}\text { Hosmer-Lemeshow goodness } \\
\text { of fit }\end{array}$ & $\begin{array}{l}\mathrm{Chi}^{2}(6)=2.726 \\
(P=.842)\end{array}$ & $\operatorname{Chi}^{2}(4)=0.249,(P=.993)$ & $\begin{array}{l}\operatorname{Chi}^{2}(0)=0.000 \\
(-)\end{array}$ & $\begin{array}{l}\operatorname{Chi}^{2}(8)=3.401 \\
(P=0.901)\end{array}$ \\
\hline
\end{tabular}

incomplete picture of their perception of the multiple diseases they have, and possibly also a lack of insight in aspects that are particularly relevant for their perception of multimorbidity, for instance beliefs about common causal factors or interactions between conditions or treatments. On the other hand, many people with multimorbidity seem unable to disentangle their conditions
[56], as their perception of illness is different from healthcare professionals' disease constructs [57].

Furthermore, the self-reported use of health services may be considered a limitation of the study. Participants were asked in April 2017 to report the number of contacts with the general practice, the use of general practice out-of-office services and any unplanned

Table 5 Proportions of cases correctly predicted (sensitivity and specificity) for various classification cut-offs

\begin{tabular}{|c|c|c|c|c|c|}
\hline & $\begin{array}{l}\text { Frequent contact with } \\
\text { general practice }\end{array}$ & $\begin{array}{l}\text { Use of general practice out-of- } \\
\text { office service }\end{array}$ & $\begin{array}{l}\text { Unplanned } \\
\text { hospitalisation }\end{array}$ & \multicolumn{2}{|c|}{$\begin{array}{l}\text { Poor health related } \\
\text { quality of life }\end{array}$} \\
\hline Final model & $\begin{array}{l}\operatorname{Chi}^{2}(3)=21.512 \\
(P<.001)\end{array}$ & $\begin{array}{l}\operatorname{Chi}^{2}(3)=16.037 \\
(P=.001)\end{array}$ & $\begin{array}{l}\operatorname{Chi}^{2}(1)=9.654 \\
(P=.002)\end{array}$ & \multicolumn{2}{|c|}{$\begin{array}{l}\operatorname{Chi}^{2}(7)=137.288 \\
(P<.001)\end{array}$} \\
\hline N & 552 & 577 & 580 & \multicolumn{2}{|l|}{541} \\
\hline AUC & .626 & .612 & .609 & \multicolumn{2}{|l|}{.837} \\
\hline Classification cut-off: & & & & Sens. ${ }^{a}$ & Spec.' \\
\hline .10 & & & & 90.8 & 57.2 \\
\hline .15 & & & & 81.7 & 67.6 \\
\hline .16 & & & & 80.7 & 68.1 \\
\hline .17 & & & & 79.8 & 69.7 \\
\hline .20 & & & & 74.3 & 75.2 \\
\hline .25 & & & & 67.9 & 82.2 \\
\hline .50 & & & & 43.1 & 94.0 \\
\hline
\end{tabular}

a Sens. = Sensitivity: number of cases predicted with adverse outcome / total number of cases observed with adverse outcome

${ }^{\mathrm{b}}$ Spec. = Specificity: number of cases not predicted with adverse outcome / total number of cases not observed with adverse outcome 
hospitalisations in 2016. Recall bias may have occurred. Comparing our self-reported data with data of more than 200,000 multimorbid patients registered in a general practice database and hospital registrations in 2013 show nevertheless high resemblance: in this study we found $23 \%$ with nine or more contacts with the general practice and $9 \%$ with unplanned hospitalisations, whereas this was respectively 20 and $7 \%$ in the registered data of 2013 [19].

Another issue is that participants reported in April 2017 their use of health services in 2016, while data about their illness perceptions and personal resources were collected in 2016. Given that data about illness perceptions and resources were predominantly collected by a survey in April 2016, it seems likely that the largest part of their health service use in 2016 took place after this survey. It is possible however that participants had contact with the general practice out-of-office service or had an unplanned hospitalisation before assessment of their illness perceptions and resources. Illness perceptions and resources are usually however rather stable, once developed.

A final remark concerns the need to validate our results. Given its size, we could not randomly split the sample to create two data sets, to respectively build and validate our prediction models. We recently initiated new data collection among adult patients with multimorbidity who participate in a quality improvement initiative of a group of general practices in the Netherlands for the purpose of validation.

\section{Recommendations for future research}

Some of the limitations of our study may be solved by future research. First, there is a need to develop and validate a questionnaire for people with multimorbidity that covers the broad spectrum of their perceptions of multimorbidity. Promising work has been done in the United Kingdom with the development of the Multimorbidity Illness Perceptions Scale (MULTIPleS) [58], but further testing of its construct and predictive validity is needed. Moreover, translation and cross-cultural validation will be necessary in order to make this questionnaire suitable for use in other countries. Second, to identify high-need patients it would be a big step forward to link clinical registration data and patient-reported data of general practice patients with multimorbidity and analyse these data together. In this way it could be more reliably assessed whether people with high needs as reflected by their use of particular health services are indeed different from people with high needs as reflected by patientreported outcomes, such as health related quality of life. Finally, we wish to emphasise the necessity to conduct effectiveness studies on integrated care pathways among high-need patient populations. There is still limited evidence of which types of (integrated) care are effective to improve health related outcomes and optimal use of health services among multimorbid patient populations $[59,60]$. Such evidence is of utmost importance, as identifying high-need patients only makes sense, if there is evidence based support for GPs on which care these people are most likely to benefit from.

\section{Relevance for clinical practice}

Based on this study, we designed a brief screener to identify persons who are likely to develop a poor health related quality of life in the near future among adults with two or more chronic conditions, which could be applied by the GP or practice nurse together with the patient. This screener consists of seven questions: four derived from the BIPQ (perceived consequences, personal control, concern and emotional response) [41], one from the HADSDepression scale [48] and two self-developed items on mastery and perceived social support. Item scoring and the classification cut-off score are based on the current study. The screening result could be used to invite patients for one or more person-centred consultations and/ or follow-up care, as agreed upon with the patient. Feasibility of using the screener is currently being piloted.

Irrespective of using a screener, we strongly advise healthcare professionals to explore the illness perceptions and personal resources of their patients with multimorbidity regularly, in particular their control beliefs, attributed symptoms, concerns and emotional response to their illness and their support network, mental health and sense of mastery. Financial issues related to service use and health literacy may also be explored in subgroups of patients or deprived areas.

\section{Conclusions}

People with multimorbidity at risk of a poor health related quality of life are for a large part not the same people who frequently contact the general practice, visit the general practice out-of-office service or have unplanned hospitalisations, or vice versa. As these four high-need subgroups show different characteristics, there is no common set of illness beliefs or personal resources that satisfactorily predict all four outcomes. Persons with multimorbidity who have a high risk of developing a poor health related quality of life can be identified by their specific illness beliefs (attribution of many symptoms to their chronic conditions, a high level of concern and little perceived control over their illness), a poor mental health status and unmet social needs.

\section{Supplementary information}

Supplementary information accompanies this paper at https://doi.org/10. 1186/s12875-020-01148-3.

Additional file 1. Detailed description of statistical analyses. 


\section{Abbreviations}

AE (subscale): Active Engagement with healthcare providers (Health Literacy Questionnaire); AMH (subscale): Actively Managing Health (Health Literacy Questionnaire); AUC: Area Under the Curve; BIPQ: Brief Illness Perception Questionnaire; CCMO: Central Committee on Research Involving Human Subjects; COPD: Chronic Obnstructive Pulmonary Disease; CA (subscale): Critical Appraisal (Health Literacy Questionnaire); EHR: Electronic Health Record; EQ-5D: EuroQuol 5 Dimensions questionnaire; EQ-5D-5 L: 5level EQ-5D version; FHI (subscale): ability to Find good Health Information (Health Literacy Questionnaire); HADS: Hospital Anxiety and Depression Scale; HPS (subscale): Healthcare Provider Support (Health Literacy Questionnaire); HSI (subscale): Having Sufficient Information (Health Literacy Questionnaire); HKQ: Health Literacy Questionnaire; ICPC: International Classification of Primary Care; GP: general practitioner; MULTIPleS: Multimorbidity Illness Perceptions Scale; N: number; NHS (subscale): Navigating the Healthcare System (Health Literacy Questionnaire); NPCD: National Panel of people with Chronic illness or Disability; OR: Odds Ratio; ROC (analysis): Receiver Operating Characteristic (analysis); SD: standard deviation; Sens.: Sensitivity; Spec.: Specificity; SS (subscale): Social Support (Health Literacy Questionnaire); UHI (subscale): reading and Understanding Health Information (Health Literacy Questionnaire); WHO: World Health Organization; WMO: Medical Research Involving Human Subjects Act

\section{Acknowledgements}

We thank all general practitioners and patients participating in the National Panel of people with Chronic illness or Disability (NPCD) in the Netherlands.

\section{Authors' contributions}

MR designed the study, conducted the statistical analyses, contributed to the interpretation of the data, and drafted the manuscript. JMV, MH, FS and JK contributed to the design of the study and the interpretation of the data, commented on various drafts and revised the manuscript critically. All authors approved the final manuscript and agree to be accountable for all aspects of the study.

\section{Funding}

Funding of this study was provided by the Netherlands ministry of Health, which did not interfere in the study design, study implementation or the writing of this article.

\section{Availability of data and materials}

The dataset analysed for the current study is available from the corresponding author on reasonable request.

\section{Ethics approval and consent to participate}

The study was carried out according to the precepts of the Helsink Declaration and Dutch legislation on privacy. The panel-study is registered with the Dutch Data Protection Authority (registration no. 1283171); all data were collected and handled in accordance with the privacy protection guidelines of the Authority. Patients gave written informed consent to participate in the panel-study. According to the Central Committee on Research Involving Human Subjects (CCMO), the panel-study is not subject to the Medical Research Involving Human Subjects Act (WMO), which entails that approval by a Medical Ethics Committee was not obligatory for this study (www.english.ccmo.nl)

\section{Consent for publication}

Not applicable.

\section{Competing interests}

The authors declare that they have no competing interests.

\section{Author details}

${ }^{1}$ Nivel (Netherlands Institute for Health Services Research), PO Box 1568, 3500, BN, Utrecht, The Netherlands. ${ }^{2}$ Department of Health and Social Management, University of Eastern Finland, Kuopio, Finland. ${ }^{3}$ Health Services \& Policy Research, Exeter Collaboration for Academic Primary Care (APEx), NIHR PenCLAHRC, University of Exeter, Exeter, UK. ${ }^{4}$ Department of General Practice and Elderly Care Medicine, Amsterdam UMC, Amsterdam, The Netherlands.
Received: 15 September 2019 Accepted: 22 April 2020

Published online: 29 April 2020

\section{References}

1. van den Akker M, Buntinx F, Knottnerus JA. Comorbidity or multimorbidity: what's in a name? A review of literature. Eur J General Practice. 1996;2:65-70.

2. Tsiachristas A, van Ginneken E, Rijken M. Tackling the challenge of multimorbidity: actions for health policy and research. Health Policy. 2018;122:1-3.

3. Wolff J, Starfield B, Anderson G. Prevalence, expenditures, and complications of multiple chronic conditions in the elderly. Arch Intern Med. 2002;162: 2269-76.

4. Fortin M, Lapointe L, Hudon C, et al. Multimorbidity and quality of life in primary care: a systematic review. Health Qual Life Outcomes. 2004;2:51.

5. Rijken M, van Kerkhof M, Dekker J, et al. Comorbidity of chronic diseases: effects of disease pairs on physical and mental functioning. Qual Life Res. 2005;14:45-55.

6. Schofield DJ, Callander EJ, Shrestha RN, et al. Multiple chronic health conditions and their link with labour force participation and economic status. PLoS One. 2013;8:e79108.

7. Uijen AA, van de Lisdonk EH. Multimorbidity in primary care: prevalence and trend over the last 20 years. Eur J General Practice. 2008;14(Suppl. 1): 28-32.

8. King DE, Xiang J, Pilkerton CS. Multimorbidity trends in United States adults, 1988-2014. J Am Board Fam Med. 2018;31:503-13.

9. Wang L, Si L, Cocker F, Palmer AJ, et al. A systematic review of cost-ofillness studies of multimorbidity. Applied Health Economics and Health Policy. 2017;16(2):1-15.

10. Cassell A, Edwards D, Harshfield A, et al. The epidemiology of multimorbidity in primary care: a retrospective cohort-study. $\mathrm{Br} J$ General Practice 2018. https://doi.org/10.3399/bjgp18X695465.

11. Payne RA, Abel GA, Guthrie B, et al. The effect of physical multimorbidity, mental health conditions and socioeconomic deprivation on unplanned admissions to hospital: a retrospective cohort study. CMAJ. 2013;185:e221-8.

12. Barnett K, Mercer SW, Norbury M, et al. Epidemiology of multimorbidity and implications for health care, research, and medical education: a crosssectional study. Lancet. 2012;380:37-43.

13. Glynn $L G$, Valderas $J M$, Healy $P$, et al. The prevalence of multimorbidity in primary care and its effect on health care utilization and cost. Fam Practice. 2011;28:516-23.

14. Salisbury C. Multimorbidity: redesigning health care for people who use it. Lancet. 2012;380:7-9.

15. Tinetti ME, Fried TR, Boyd CM. Designing health care for the most common chronic condition - multimorbidity. JAMA. 2012;307:2493-4.

16. van der Heide I, Snoeijs SP, Boerma WGW, et al. How to strengthen patientcentredness in caring for people with multimorbidity in Europe? Health systems and policy analysis, policy brief 22. WHO/European Observatory on Health Systems and Policies: Copenhagen; 2017.

17. Valderas JM. Getting impatient about person-centred health care. Eur J General Practice. 2013;19:141-2.

18. Bleijenberg $\mathrm{N}$, ten Dam VH, Steunenberg B, et al. Exploring the expectations, needs and experiences of general practitioners and nurses towards a proactive and structured care programme for frail older patients: a mixed-methods study. J Advanced Nursing. 2013:2262-73.

19. Heins $M$, Rijken $M$, Valderas J, et al. Identifying high-need patients with multimorbidity based on their primary care medical records (p. 37). https:// www.egprn.org/file/e7db36b0-f56e-4324-b9e1-3b48898daf33/ProgrammeBook-of-the-88th-EGPRN-Meeting-Tampere-Finland-9-12-May-2019.pdf.

20. Leventhal H, Meyer D, Nerenz D. The common sense representation of illness danger. In: Rachman S, editor. Medical Psychology, vol. 2. New York: Pergamon Press; 1980. p. 7-30,

21. Broadbent E, Donkin L, Stroh JC. Illness and treatment perceptions are associated with adherence to medications, diet, and exercise in diabetic patients. Diabetes Care. 2011;34:338-40.

22. van Puffelen AL, Heijmans MJWM, Rijken M, et al. Illness perceptions and self-care behaviours in the first years of living with type 2 diabetes; does the presence of complications matter? Psychol Health. 2015;30:1274-87.

23. Chilcot J, Wellsted D, Farrington K. Illness representations are associated with fluid nonadherence among hemodialysis patients. J Psychosom Res. 2010;68:203-12.

24. Aulja N, Walker M, Sprigg N, et al. Can illness beliefs, from the commonsense model, prospectively predict adherence to self-management 
behaviours? A systematic review and meta-analysis. Psychol Health. 2016;31: 931-58.

25. Mounce LT, Campbell JL, Henley WE, et al. Predicting incident multimorbidity. Ann Fam Med. 2018;16:322-9.

26. Foxwell R, Morley C, Frizelle D. Illness perceptions, mood and quality of life: a systematic review of coronary heart disease patients. J Psychosom Res. 2013;75:211-22

27. Mewes R, Rief W, Kenn K, et al. Psychological predictors for health-related quality of life and disability in persons with chronic obstructive pulmonary disease (COPD). Psychol Health. 2016;31:470-86.

28. McSharry J, Moss-Morris R, Kendrick T. Illness perceptions and glycaemic control in diabetes: a systematic review with meta-analysis. Diabetic Med. 2011;28:1300-10

29. Jayanti A, Foden P, Wearden A, et al. Illness beliefs in end stage renal disease and associations with self-care modality choice. PLoS One. 2016;11: e0154299.

30. Lowe R, Porter A, Snooks, et al. The association between illness representation profiles and use of unscheduled urgent and emergency health services. Br J Health Psychol. 2011;16:862-79.

31. Schuz B, Wurm S, Warner LM, et al. Multiple illness perceptions in older adults: effects on physical functioning and medication adherence. Psychol Health. 2012;27:442-57.

32. Gershon AS, Dolmage TE, Stephenson A, et al. Chronic obstructive pulmonary disease and socioeconomic status: a systematic review. COPD. 2012;9:216-26.

33. Callander EJ, McDermott R. Measuring the effects of CVD interventions and studies across socioeconomic groups: a brief review. Int J Cardiol. 2017;227: 635-43.

34. Mielck A, Vogelmann M, Leidl R. Health-related quality of life and socioeconomic status: inequalities among adults with a chronic disease. Health Qual Life Outcomes. 2014;12:58.

35. Hopman P, Schellevis FG, Rijken M. Health-related needs of people with multiple chronic diseases: differences and underlying factors. Qual Life Res. 2016;25:651-60.

36. Jansen DL, Heijmans M, Rijken M. Individual care plans for chronically ill patients within primary care in the Netherlands: dissemination and associations with patient characteristics and patient-perceived quality of care. Sc J Prim Health Care. 2015;33:100-6.

37. Lamberts M. Wood M. ICPC. International classification of primary care. Oxford: Oxford University Press; 1987.

38. O'Halloran J, Miller GC, Britt H. Defining chronic conditions for primary care with ICPC-2. Fam Practice. 2004;21:381-6 Supplementary data.

39. Herdman M, Gudex C, Lloyd A, et al. Development and preliminary testing of the new five-level version of EQ-5D (EQ-5D-5L). Qual Life Res. 2011;20: 1727-36.

40. Versteegh MM, Vermeulen KM, Evers SMAA, et al. Dutch tariff for the fivelevel version of EQ-5D. Value Health. 2016;19:343-52.

41. Broadbent E, Petrie KJ, Main J, et al. The brief illness perception questionnaire. J Psychosom Res. 2006;60:631-7.

42. de Jong-Gierveld J, van Tilburg T. Manual of the loneliness scale 1999. Update from the printed version: 15-6-2017. Amsterdam: VU University; 1999. http://home.fsw.vu.nl/TG.van.Tilburg/manual_loneliness_scale_1999.html.

43. Gfk. Aanvullend Voorzieningengebruik Onderzoek 2003. Onderzoeksverantwoording. Dongen: Gfk 2004.

44. World Health Organization. Health promotion glossary. Health Promot Int 1998;13:349-64.

45. Osborne RH, Batterham RW, Elsworth GR, et al. The grounded psychometric development and initial validation of the health literacy questionnaire (HLQ). BMC Public Health. 2013;13:658.

46. Pearlin LI, Schooler C. The structure of coping. J Health Social Behavior. 1978;19:2-21.

47. Mastery. Longitudinal Aging Study Amsterdam. https://www.lasa-vu.nl/ themes/emotional/mastery.html. Accessed 24 Apr 2020.

48. Zigmond AS, Snaith RP. The hospital anxiety and depression scale. Acta Psychiatrica Scand. 1983;67:361-70.

49. Bjelland I, Dahl AA, Haug $\Pi$, et al. The validity of the hospital anxiety and depression scale. An updated literature review. J Psychosom Res. 2002;52: 69-77.

50. Broadbent $\mathrm{E}$, Wilkes $\mathrm{C}$, Koschwanez $\mathrm{H}$, et al. A systematic review and metaanalysis of the brief Ilness perception questionnaire. Psychol Health. 2015;30: $1361-85$.
51. Sawyer AT, Harris SL, Koenig HG. Illness perception and high readmission health outcomes. Health Psychol Open. 2019;6(1):2055102919844504. https://doi.org/10.1177/2055102919844504.

52. Petrie KJ, Jago LA, Devcich DA. The role of illness perceptions in patients with medical conditions. Curr Opinion Psychiatry. 2007;20:163-7.

53. Thong MSY, Mols F, Kaptein AA, et al. Illness perceptions are associated with higher health care use in survivors of endometrial cancer - a study from the population-based PROFILES registry. Support Cancer Care. 2019;27: 1935-44.

54. Jansen T, Rademakers J, Waverijn G, et al. The role of health literacy in explaining the association between educational attainment and the use of out-of-office hours primary care services in chronically ill people: a survey study. BMC Health Serv Res. 2018;18:394. https://doi.org/10.1186/s12913018-3197-4

55. Rijken $\mathrm{M}$, van der Heide I. Identifying subgroups of persons with multimorbidity based on their needs for care and support. BMC Fam Pract. 2019;20:179.

56. Vos RC, Kasteleyn MJ, Heijmans MJ, et al. Disentangling the effects of illness perceptions on health status in people with type 2 diabetes after a coronary event. BMC Fam Practice. 2018;19:35.

57. Bower P, Harkness E, Macdonals W, et al. Illness representations in people with multi-morbid long-term conditions: qualitative study. Psychol Health. 2012;27:1211-26.

58. Gibbons CJ, Kenning C, Coventry PA, Bee P, Bundy C, Fisher L, Bower P. Development of a multimorbidity illness perceptions scale (MULTIPleS). PLoS One. 2013:8(12):e81852.

59. Smith SM, Wallace E, O'Dowd T, Fortin M. Interventions for improving outcomes in patients with multimorbidity in primary care and community settings. Cochrane Database of Systematic Reviews 2016, Issue 3. Art. No.: CD006560.

60. Hopman P, de Bruijn SR, Forjaz MJ, Rodriguez-Blazquez C, Tonnara G, Lemmens LC, Onder G, Baan CA, Rijken M. Effectiveness of comprehensive care programs for patients with multiple chronic conditions or frailty: a systematic literature review. Health Policy. 2016;120:818-32.

\section{Publisher's Note}

Springer Nature remains neutral with regard to jurisdictional claims in published maps and institutional affiliations.

\section{Ready to submit your research? Choose BMC and benefit from:}

- fast, convenient online submission

- thorough peer review by experienced researchers in your field

- rapid publication on acceptance

- support for research data, including large and complex data types

- gold Open Access which fosters wider collaboration and increased citations

- maximum visibility for your research: over $100 \mathrm{M}$ website views per year

At BMC, research is always in progress.

Learn more biomedcentral.com/submissions 